\title{
ARISE to supportive psychotherapy
}

\author{
Melissa Neumann, MD, Nicole Silva, MD, and Douglas J. Opler, MD
}

Dr. Neumann is a PGY-1 Internal Medicine Resident, Zucker School of Medicine, North Shore University Hospital/ Long Island Jewish Medical Center, Uniondale, New York. Dr. Silva is a PGY-1 Neurosurgery Resident, University of North Carolina, Chapel Hill, North Carolina. Dr. Opler is Assistant Professor of Psychiatry, Rutgers New Jersey Medical School, Newark, New Jersey.

\section{Disclosures}

The authors report no financial relationships with any companies whose products are mentioned in this article, or with manufacturers of competing products.

doi: 10.12788/cp.0123

\section{f}

Discuss this article at www.facebook.com/ MDedgePsychiatry 6
S upportive psychotherapy is a common type of therapy that often is used in combination with other modalities. By focusing on improving symptoms and accepting the patient's limitations, it is particularly helpful for individuals who might have difficulty engaging in insight-oriented psychotherapies, such as those struggling with external stressors, including exposure to trauma, bereavement, physical disabilities, or socioeconomic challenges. Personal limitations, including severe personality disorder or intellectual disabilities, might also limit a patient's ability to self-reflect on subconscious issues, which can lead to choosing a supportive modality.

While being supportive in the vernacular sense can be helpful, formal supportive psychotherapy employs well-defined goals and techniques. ${ }^{1}$ A therapist can facilitate progress by explicitly referring to these goals and techniques. The acronym ARISE can help therapists and other clinicians to use and appraise therapeutic progress toward these goals.

A lliance-building. The therapeutic alliance is an important predictor of the success of psychotherapy. ${ }^{2}$ Warmly encourage positive transference toward the therapist. The patient's appreciation of the therapist's empathic interactions can further the alliance. Paraphrasing the patient's words can demonstrate and enhance empathy. Doing so allows clarification of the patient's thoughts and helps the patient feel understood. Formulate and partner around shared therapeutic goals. Monitor the strength of the alliance and intervene if it is threatened. For example, if you misunder- stand your patient and inadvertently offend them, apologizing may be helpful. In the face of disagreement between the patient and therapist, reorienting back to shared goals reinforces common ground.

Reduce anxiety and negative affect. In contrast to the caricature of the stiff psychoanalyst, the supportive therapist adopts an engaged conversational style to help the patient feel relaxed and to diminish the power differential between therapist and patient. If the patient appears uncomfortable with silence, maintaining the flow of conversation may reduce discomfort. ${ }^{1}$ Minimize your patient's discomfort by approaching uncomfortable topics in manageable portions. Seek permission before introducing a subject that induces anxiety. Explain the reasoning behind approaching such topics. $^{3}$ Reassurance and encouragement can further reduce anxiety. ${ }^{4}$ When not incongruous to the discussion, appropriate use of warm affect (eg, a smile) or even humor can elicit positive affect.

Increase awareness. Use psychoeducation and psychological interpretation (whether cognitive-behavioral or psychodynamic) to expand your patient's awareness and help them understand their social contacts' point of view. Clarification, gentle confrontation, and interpretation can make patients aware of biopsychosocial precipitants of distress. ${ }^{4}$

Strengthen coping mechanisms. Reinforce adaptive defense mechanisms, such as mature humor or suppression. Educating patients on practical organizational skills, 
problem-solving, relaxation techniques, and other relevant skills, can help them cope more effectively. Give advice only in limited circumstances, and when doing so, back up your advice with a rationale derived from your professional expertise. Because it is important for patients to realize that their life choices are their own, usually it is best to help the patient understand how they might come to their own decisions rather than to prescribe life choices in the form of advice.

\section{Enhance self-esteem. Many patients} in distress suffer from low self-esteem. ${ }^{5,6}$ Active encouragement and honest praise can nurture your patient's ability to correct a distorted self-image and challenge selfreproach. Praise should not be false but reality-based. Praise can address preexist- ing strengths, highlight the patient's willingness to express challenging material, or provide reinforcement on progress made toward treatment goals.

\section{References}

1. Rothe, EM. Supportive psychotherapy in everyday clinical practice: it's like riding a bicycle. Psychiatric Times. Published May 24, 2017. Accessed April 12, 2021. https: / / www.psychiatrictimes.com/view/supportivepsychotherapy-everyday-clinical-practice-its-riding-bicycle

2. Flückiger C, Del Re AC, Wampold BE, et al. The alliance in adult psychotherapy: a meta-analytic synthesis. Psychotherapy (Chic). 2018;55(4):316-340.

3. Pine F. The interpretive moment. Variations on classical themes. Bull Menninger Clin. 1984;48(1), 54-71.

4. Grover S, Avasthi A, Jagiwala M. Clinical practice guidelines for practice of supportive psychotherapy. Indian J Psychiatry. 2020;62(Suppl 2):S173-S182.

5. Leary MR, Schreindorfer LS, Haupt AL. The role of low selfesteem in emotional and behavioral problems: why is low self-esteem dysfunctional? J Soc Clin Psychol. 1995;14(3): 297-314.

6. Zahn R, Lythe KE, Gethin JA, et al. The role of self-blame and worthlessness in the psychopathology of major depressive disorder. J Affect Disord. 2015;186:337-341.
Seek your

patient's

permission before introducing

a topic that induces anxiety 